EDITORIAL

\title{
Aniversarios y pandemia de COVID-19: Revista Médica Hondureña, LILACS y la Biblioteca Virtual en Salud de Honduras
}

\author{
Anniversaries and COVID-19 pandemic: Revista Médica Hondureña, LILACS and the Honduras Virtual Health Library
}

En 2020, año de la pandemia de COVID-19, conmemoramos tres aniversarios relevantes: 90 Aniversario de la Revista Médica Hondureña (RMH, https://revistamedicahondurena.hn/), 35 Aniversario de la base de datos Literatura Latinoamericana y del Caribe en Ciencias de la Salud (LILACS, https://lilacs. bvsalud.org/es/) y 20 Aniversario de la Biblioteca Virtual en Salud de Honduras (BVS-HN, http://www.bvs.hn/). Estas tres entidades están interconectadas y cada una contribuye con el desempeño de las otras dos.

La RMH, fundada en noviembre de 1929, publicó su primer número en mayo de $1930 .{ }^{1}$ Después de implementar una serie de adaptaciones para mejorar los parámetros de normalización, fue la primer revista nacional indexada en LILACS y a partir del año 2000, de manera escalonada hasta completar todos los números, es desplegada digitalmente en la BVS-HN (http://www.bvs.hn/RMH/html5/). La indexación en LILACS y su acceso en línea han sido transcendentales para la mejora continua, visibilidad y posicionamiento de la RMH como fuente de información a nivel nacional e internacional. Además, a partir de 2019 se hospeda en un sitio web gestionado por el Colegio Médico de Honduras (https://revistamedicahondurena.hn/). Se resalta como fortaleza, contar con revisión de las referencias bibliográficas y de su citación por el personal de la Biblioteca Médica Nacional (BIMENA). Este es un proceso continuo que se mantiene aún en tiempo de pandemia.

LILACS, es la base de datos más extensa e importante de la región. ${ }^{2}$ Reúne diversos documentos publicados a partir de 1982, incluyendo artículos de revistas con revisión par, tesis y disertaciones, documentos gubernamentales, anales de congresos y libros. Coordinada por el Centro Latinoamericano y del Caribe de Información en Ciencias de la Salud (BIREME) de OPS/OMS, es mantenida y actualizada por una red de instituciones académicas, gubernamentales y de investigación en salud, distribuidas en los países de la región. LILACS es fuente de información indispensable en la búsqueda de estudios primarios en la región y complementa las bases de datos MEDLINE/PubMed. BIMENA es el Centro Coordinador Nacional para LILACS en Honduras.

La BVS-HN es un esfuerzo cooperativo de instituciones públicas y privadas de salud, coordinadas por un Comité Consultivo, con apoyo técnico de OPS y colaboración del Colegio Médico de Honduras y otras instituciones nacionales. ${ }^{3}$ La BVS-HN tiene el objetivo de contribuir al mejoramiento de la salud de los hondureños brindando información de calidad. Adicionalmente, integra la red regional de bibliotecas virtuales en salud y sobresale brindando apoyo técnico a otras bibliotecas virtuales de la región.

Mediante el proceso de control bibliográfico establecido por LILACS, la orientación continua y oportuna brindada por BIMENA atendiendo los criterios establecidos, la RMH realiza mejoras en contenido, parámetros de normalización y procesos editoriales. Asimismo, editores, revisores y autores, se benefician de las actividades de capacitación brindadas por LILACS y BIMENA. Además, la digitalización y los procesos de control presencial y remoto realizados por ambas instancias, le han permitido estar mejor preparada para afrontar este tiempo de pandemia que amerita dar respuesta a situaciones inéditas y cambiantes, para brindar una revisión oportuna y adecuada a un mayor volumen editorial custodiando la calidad de la evidencia científica. Una realidad global. ${ }^{4}$ En la actualidad, la RMH mantiene su periodicidad semestral puntualmente, con miras a aumentar su visibilización en índices y bases de datos internacionales.

Para conmemorar el Aniversario 90, este Suplemento presenta artículos que resaltan aportes a las ciencias de la salud desde la RMH y se rinde homenaje a los colegas fallecidos por la pandemia de COVID-19. Asimismo, en los números del Volumen 88 se publican artículos que la destacan como fuente de información para conocer el desarrollo y evolución en el campo de la salud desde inicios del Siglo XX en Honduras.

Jackeline Alger, MD, PhD

Directora

Revista Médica Hondureña

\section{REFERENCIAS}

1. Javier Zepeda CA. Reseña Histórica de la Revista Médica Hondureña 1930-2005. Rev Méd Hondur. 2005;73(Supl 2):4-16.

2. Centro Latinoamericano y del Caribe de Información en Ciencias de la Salud. LILACS, Literatura Latinoamericana y del Caribe en Ciencias de la Salud [Internet]. Brasil: BIREME; 2020. [consultado 17 octubre 2020]. Disponible en: https://lilacs.bvsalud.org/

3. Acerca de la Biblioteca Virtual en Salud de Honduras. [Internet]. Tegucigalpa: BIMENA; 2020. [consultado 17 octubre 2020]. Disponible en: http:// www.bvs.hn/php/level.php?lang=es\&component=19\&item=2

4. Leiva-Cepas F, Romero-Rodríguez E, Barroso Sevillano M [Editorial]. Las revistas científicas ante la pandemia por COVID-19. Medicina de Familia (SEMERGEN) [Internet]. 2020[consultado 17 octubre 2020]:;46(S1):1-2. Disponible en: https://www.ncbi.nlm.nih.gov/pmc/articles/PMC7328551/ $\mathrm{pdf} / \mathrm{main} . \mathrm{pdf}$ 